\title{
Assessment of adequacy of intraoperative nodal staging and factors influencing the lack of its compliance with recommendations in the surgical treatment of non-small cell lung cancer (NSCLC)
}

\author{
Konrad Pawelczyk ${ }^{1}$, Piotr Blasiak ${ }^{1}$, Monika Szromek ${ }^{1}$, Katarzyna Nowinska ${ }^{2}$, Marek Marciniak $^{1}$ \\ ${ }^{1}$ Wroclaw Medical University, Department of Thoracic Surgery, Wroclaw Thoracic Surgery Centre, Wroclaw, Poland; ${ }^{2}$ Department of Histology \\ and Embryology, Wroclaw Medical University, Wroclaw, Poland \\ Contributions: (I) Conception and design: K Pawelczyk, M Marciniak; (II) Administrative support: K Pawelczyk, P Blasiak, K Nowinska; (III) \\ Provision of study materials or patients: K Pawelczyk, P Blasiak, M Szromek; (IV) Collection and assembly of data: K Pawelczyk, P Blasiak, M \\ Szromek; (V) Data analysis and interpretation: K Pawelczyk, K Nowinska, M Marciniak; (VI) Manuscript writing: All authors; (VII) Final approval of \\ manuscript: All authors. \\ Correspondence to: Konrad Pawełczyk. Wroclaw Medical University, Department of Thoracic Surgery, Wroclaw Thoracic Surgery Centre, ul. \\ Grabiszyńska 105, 53-439 Wroclaw, Poland. Email: kopaw@wp.pl.
}

\begin{abstract}
Background: Adequate pathological status of lymph nodes sampled during resection of NSCLC determines prognosis and decides on further therapeutic actions. The areas of analysis are the factors affecting evaluation of $\mathrm{pN}$ accuracy, and the convergence of recommendations with actual intraoperative sampling of lymph nodes.

Methods: The data of 3,215 patients with NSCLC consecutively operated with the intention of radical resection in 2007-2017, were analyzed. Accuracy of nodal sampling and influencing factors were compared with Union for International Cancer Control (UICC) guidelines, which recommend that to confirm pN0 status at least six lymph nodes/stations free of the disease must be removed. Three should be sampled from mediastinum (including subcarinal) and three from N1 stations.

Results: A significant number of patients were found to have an adequate staging, especially after 2009, in terms of recommended quantity of nodes/nodal stations $(\mathrm{P}<0.0001)$. Age $\geq 64(\mathrm{P}=0.048)$, left side $(\mathrm{P}<0.0001)$, sublobar resection $(\mathrm{P}<0.0001)$, T1 tumors $(\mathrm{P}=0.019)$ are the factors affecting inadequacy of staging. Patients with inaccurate staging were found to have a considerably lower $\mathrm{pN} 1(7.2 \%$ s. $15.9 \%, \mathrm{P}<0.001)$ and $\mathrm{pN} 2$ (9.7\% vs.13.4\%, $\mathrm{P}<0.001)$ status. Survival of patients with inadequate staging were found to be significantly worse $(\mathrm{P}=0.0002)$, which resulted in worse survival of those patients in stage $\mathrm{I}(\mathrm{P}=0.00004)$, stage II $(\mathrm{P}=0.023)$ and stage III $(\mathrm{P}=0.031)$ of NSCLC.

Conclusions: UICC recommendations led to an increased adequacy of nodal sampling. The factors affecting insufficient number of sampled nodes include advanced age, left side, sublobar resections and T1 stage. Inaccuracy of intraoperative nodal staging results in incorrect prognosis.
\end{abstract}

Keywords: Non-small cell lung cancer (NSCLC); staging adequacy; nodal sampling

Submitted May 11, 2018. Accepted for publication Jun 29, 2018.

doi: $10.21037 /$ jtd.2018.07.23

View this article at: http://dx.doi.org/10.21037/jtd.2018.07.23 


\section{Introduction}

It is a common fact that a precise determination of the pathological $\mathrm{N}$ status is a crucial prognostic and therapeutic feature in patients surgically treated due to NSCLC. Intraoperative sampling of a proper number of mediastinal and hilar/intrapulmonary lymph nodes results in accurate $\mathrm{N}$ category staging. Currently there exist no evidence-based guidelines defining the number of nodes and the location of node stations, which should definitely be sampled in order to exclude positive $\mathrm{N}$ status. Current recommendations require at least sampling of mediastinal lymph nodes and N1 group (1-3).

Guidelines presented by Union for International Cancer Control (UICC) assume intraoperative sampling and exclusion of metastasis in at least six nodes/node stations in order to confirm the pathological N0 category. Three of the sampled nodes/stations should be taken from mediastinum (including subcarinal nodes), and three from nodes/stations of hilar/intrapulmonary area (1). The convergence of recommendations concerning the evaluation of mediastinal and hilar/intrapulmonary lymph nodes, as well as actually performed intraoperative sampling has not so far been widely analysed. The data from the National Registry of Lung Cancer has therefore been analysed to determine the quantities of nodes/stations sampled in high volume thoracic surgery centre in Wroclaw, south-western Poland. The centre covers the area of Lower Silesia, the population of approx. 4 million. The average number of thoracic surgeries exceeded 1,300 a year (including approx. 370 radical resections of lung cancer). The research focused on compliance of performed lymphadenectomy or sampling in surgical treatment of NSCLC taking account of the minimum necessary to obtain proper staging of $\mathrm{N}$ category as required by UICC. Other evaluated factors which may influence the accuracy of intraoperative sampling and survival rate included adequate and inadequate $\mathrm{N}$ category staging.

\section{Methods}

From January 2007 to December 2017, 3,376 consecutive patients with diagnosis of lung cancer were operated on at the Wroclaw Thoracic Surgery Centre with the intention of radical resection. From this group, 7 patients were excluded due to carcinosarcoma, 19 with small cell lung cancer, 5 with carcinoma adenoides cysticum, 33 with postchemotherapy tumor (only necrotic tissue), 6 with pleomorphic carcinoma, 12 with atypical and 79 with typical carcinoid. The data on the remaining 3,215 patients with NSCLC underwent further retrospective analysis. Histopathological reports along with clinical data were evaluated. Patients' consents were refused due the research's retrospective nature, although all patients gave their informed consent to processing the data concerning the disease by the National Registry of Lung Cancer. The approval of bioethical commission was not required as the research was not experimental in its nature.

\section{Preoperative assessment}

Preoperative staging was based on conducted chest computed tomography, PET-CT (approx. 20\% of patients), ultrasonography of abdominal cavity, in case of neurological symptoms-CT/MRI of central nervous system, in case of suspected bone metastasis - scintigraphy. Bronchofiberoscopy was carried out routinely. By 2012, mediastinoscopy was routinely performed in case of enlarged lymph nodes of mediastinum (in excess of $10 \mathrm{~mm}$ in the shortest diameter), in case of positive lymph nodes in PET-CT or centrally located tumors. EBUS-TBNA was started in 2012. A negative EBUS results were verified in mediastinoscopy. Patients were eligible for surgical treatment based on a multi-disciplinary team's decision (thoracic surgeon, radiologist, oncologist, pulmonologist and as of 2016 also radiotherapist). The patients with peripheral lesions, with no enlarged lymph nodes of mediastinum or hilum, were planned for surgical resection. The patients with confirmed metastasis to single mediastinal lymph node (single station N2 disease) were referred to chemotherapy and in case of downstaging, confirmed in a histopathological examination (mediastinoscopy) they were surgically treated. In the investigated group of 159 patients were treated with a preoperative chemotherapy due to single station N2 disease or suspected cT4.

\section{Surgical treatment and intraoperative staging}

In surgical treatment lobectomy/bilobectomy or pneumonectomy was routinely performed. In case of limited respiratory function (post-operative $\mathrm{FEV}_{1}<30 \%$, post-operative DLCO $<30 \%$ of predicted) or significant comorbidities a sublobar resection was performed (segmentectomy, wedge resection). The division of lymph nodes of mediastinum were standardized for all the years in line with the approved IASLC node map of 2009 (4). As of 2009, the Wroclaw Thoracic Surgery Centre implemented 
the recommendations compliant with UICC assumptions concerning minimum volume of lymph nodes sampled intraoperatively. In the investigated time span, patients were operated on by 15 qualified thoracic surgeons. Anatomical resections with VATS approach began in 2011. There were no patients from whom lymph nodes were not sampled. The mediastinal lymph nodes were resected "en bloc" with fatty tissue of mediastinum (especially in case of systematic lymphadenectomy), wherever it was possible to avoid defragmentation and were divided on the operating table. Each lymph node was sent for histopathological examination in a separate box. In the case the node was defragmented the material was sent in one box and sent as a single node. Group 10 and 11 were removed by surgeon. Group 12 were removed together with the lobe and then resected and examined by pathologist. Pathological staging was standardized for all cases according to the 8th TNM edition (5). The final stadium of the disease was established based on histopathological reports. Patient survival, counting from the date of operation to date of death or last follow-up was determined based on annually updated data of the National Registry of Lung Cancer.

\section{Evaluation of staging accuracy}

The number of lymph nodes and lymph nodes stations from mediastinum (mediastinal staging) and N1 group (hilum/lung staging) was evaluated. A total assessment of mediastinal staging and N1 group (overall staging) was performed. In compliance with UICC guidelines an adequate mediastinal staging was done if it included at least three lymph nodes (always subcarinal) from mediastinum. Sufficient was also sampling of at least three hilar or intrapulmonary nodes. It was determined that to confirm adequate overall $\mathrm{N}$ staging, a histopathological report should contain assessment of a minimum 6 lymph nodes: three from mediastinum (including group 7) and three from N1 group.

\section{Statistical analysis}

Evaluation of the growing trend of staging accuracy in 2007-2017 involved linear regression analysis. Test $\chi^{2}$ was used for comparing variables which might influence the volumes of sampled lymph nodes during resection, and therefore the adequacy of $\mathrm{N}$ staging. The Kaplan-Meier method was applied to obtain curves of overall survival, depending on whether the staging was regarded as adequate or not. This method was also used to determine survival rates with division of $\mathrm{N}$ category and stage of disease in relation to staging accuracy. The differences in survival were determined using a log-rank test. $\mathrm{P}$ value $<0.05$ was considered statistically significant. STATISTICA software, version 10, StatSoft Inc. was used for statistical analyses.

\section{Results}

Among 3,215 investigated patients, operated for NSCLC, an average age was 63.9 (ranged, 22-87 years), 63.4\% $(\mathrm{n}=2,039)$ were men. In $48.5 \%(\mathrm{n}=1,559)$ adenocarcinoma was diagnosed, in $35.6 \%(n=1,146)$ squamous cell carcinoma, in $8.6 \%(\mathrm{n}=275)$ large cell carcinoma, in $2.5 \%$ $(\mathrm{n}=80)$ adenosquamous carcinoma, and in $4.8 \%(\mathrm{n}=155)$ NSCLC with no subtype defined.

Table 1 illustrates the growing number of patients treated radically due to NSCLC in the investigated period. In the linear regression analysis, a statistically significant growing trend $(\mathrm{P}<0.0001)$ concerning all individually examined parameters of accuracy of staging of $\mathrm{N}$ category as proposed by UICC. A particular step forward in adequacy of overall staging of mediastinum and hilum was observed 2009 (increase in precision by $12 \%$ compared with $2008 ; 82 \%$ vs. $70 \%$ ); in successive 2010 the growth was $16 \%$ compared with 2008 (86\% vs. 70\%). In total, in the investigated group the UICC compliant staging criteria were met by 2,660 patients $(82.7 \%$ ) vs. inadequate in 555 patients (17.3\%).

Analysed factors included those which could potentially decrease the adequacy of an intraoperative lymph node sampling (Table 2). The median of the patients' age was 64. Significantly fewer cases with adequate staging were found in the group in excess of 64 years $(\mathrm{P}=0.048)$, which according to the data from division of elements comprising staging of $\mathrm{N}$ category, results mainly from a less precise exploration of hilar/intrapulmonary nodes $(\mathrm{P}=0.01)$ in this group. A greater number of patients with inadequate staging was seen in patients operated on the left side $(\mathrm{P}=0.003)$, which in turn results from a poorer exploration of mediastinal nodes on that side $(\mathrm{P}<0.0001)$ including group $7(\mathrm{P}<0.0001)$. Another factor considerably decreasing the value of $\mathrm{N}$ category staging includes sublobar resections, where at each investigated level a less precise of minimal required sampling of the nodes $(\mathrm{P}<0.0001)$. In the scope of $\mathrm{T}$ category, it was found a significantly higher number of patients with inadequate staging only in the T1 group patients $(\mathrm{P}=0.019)$. There occurred no differences staging adequacy in case of operations performed with 
Table 1 Adequacy of nodal staging in Wroclaw Thoracic Surgery Centre in the investigated period from 2007 to 2017

\begin{tabular}{lcccccccccccc}
\hline Year of surgery & 2007 & 2008 & 2009 & 2010 & 2011 & 2012 & 2013 & 2014 & 2015 & 2016 & 2017 & P value \\
\hline Number of radical resections in NSCLC & 265 & 258 & 280 & 256 & 252 & 259 & 311 & 332 & 311 & 348 & 343 & \\
$\geq 3$ mediastinal stations sampled (\%) & 64 & 68 & 76 & 76 & 71 & 77 & 83 & 85 & 85 & 86 & 82 & $<0.0001$ \\
$\geq 3$ mediastinal nodes sampled (\%) & 81 & 87 & 92 & 95 & 92 & 96 & 96 & 98 & 98 & 97 & 98 & $<0.0001$ \\
Station subcarinal sampled (\%) & 75 & 84 & 95 & 95 & 90 & 90 & 95 & 98 & 96 & 95 & 93 & $<0.0001$ \\
Adequate mediastinal staging (\%) & 74 & 80 & 92 & 93 & 87 & 88 & 93 & 97 & 95 & 94 & 92 & $<0.0001$ \\
$\geq 3$ lung/hilar stations sampled (\%) & 3 & 7 & 37 & 48 & 50 & 51 & 48 & 62 & 62 & 61 & 64 & $<0.0001$ \\
$\geq 3$ lung/hilar nodes sampled (\%) & 71 & 82 & 87 & 88 & 90 & 88 & 91 & 96 & 94 & 91 & 91 & $<0.0001$ \\
Adequate lung/hilar staging (\%) & 72 & 83 & 88 & 88 & 90 & 89 & 92 & 96 & 94 & 91 & 91 & $<0.0001$ \\
Overall adequate staging (\%) & 62 & 70 & 82 & 86 & 87 & 80 & 86 & 94 & 89 & 87 & 85 & $<0.0001$ \\
\hline
\end{tabular}

VATS approach, compared to thoracotomy. Significantly larger number of complications in case of adequate staging $(\mathrm{P}=0.027)$, which can result from an increased exploration of mediastinum and hilum (bleeding, arrhythmia, atelectasis requiring bronchoaspiration, pneumonia, bronchopleural fistula, chylothorax, recurrent laryngeal nerve palsy). Inadequate staging was also seen in patients with small tumors-the smaller the tumor the lower accuracy of staging $(\mathrm{P}<0.0001)$ which results from less effective removal of nodes from the hilum and interlobal space $(\mathrm{P}<0.0001)$ (Table 3).

Total survival in the group of patients $(\mathrm{n}=555)$ with inadequate staging was significantly worse (log-rank, $\mathrm{P}=0.0002)$. The difference also concerns mediastinal nodes sampling assessed separately in terms of compliance with the guidelines (log-rank, $\mathrm{P}=0.0004)$ and hilar/intrapulmonary group (log-rank, $\mathrm{P}=0.0001$ ) (Figure 1).

In the investigated group, a total of $72.8 \%$ patients $(\mathrm{n}=2,342)$ were found with $\mathrm{pN} 0$ category, $14.4 \%$ with $\mathrm{pN} 1(\mathrm{n}=462)$ and $12.8 \%$ with $\mathrm{pN} 2$ category $(\mathrm{n}=411)$. The number of patients with $\mathrm{pN} 1$ and $\mathrm{pN} 2$ categories was significantly higher in group of patients with properly performed intraoperative staging of $\mathrm{N}$ category $(\mathrm{P}<0.0001)$ (Table 4). Median survival in the case of adequate staging was 3,292 days for the patients with $\mathrm{pN} 0,1,222$ days for those with $\mathrm{pN} 1$ and 776 days for the patients with $\mathrm{pN} 2$. The layout of survival curves was statistically significant $(\mathrm{P}<0.000001)$ (Figure 2). In turn, the patients with inadequate staging, the median of survival for categories $\mathrm{pN} 0, \mathrm{pN} 1$ and $\mathrm{pN} 2$ was shorter (1,828, 1,074 and 655 days respectively), and in the layout of survival curves a significant difference was found $(\mathrm{P}=0.0003)$ (Figure 2).
The investigation also included the impact of adequacy of $\mathrm{N}$ category staging on survival in individual stages of NSCLC. It was found that inadequate assessment of $\mathrm{N}$ category, resulting from non-application of the minimum determined by UICC guidelines, influences prognosis and causes significant discrepancy in survival rates of patients who underwent adequate and inadequate staging in investigated stage I (log-rank, $\mathrm{P}=0.00004)$, stage II (log-rank, $\mathrm{P}=0.023$ ) and stage III (log-rank, $\mathrm{P}=0.031$ ) (Figure 3).

\section{Discussion}

Sampling of lymph nodes during radical surgical resection in NSCLC is crucial in establishing further therapeutic procedure and makes it possible to find proper prognosis in this group of patients. The necessity of sampling of lymph nodes during radical surgical resection in NSCLC raises little controversy nowadays. The controversy concerns the number of lymph nodes and the scope of their sampling. As it is necessary to properly evaluate the status of the lymph nodes and eliminate of a positive $\mathrm{N}$ category, which is of greatest prognostic importance in patients who underwent NSCLC resections (6), several recommendations determining the minimum number of nodes to be sampled intraoperatively were published. Among them are those concerning systematic nodal dissection or systematic sampling, undoubtedly allowing the most in-depth analysis of the status of mediastinal nodes. They were proposed by inter alia The European Society of Thoracic Surgeons (ESTS) in 2006 or The International Association for the Study of Lung Cancer (IASLC) in 2009 (2,7). Even though it was not proved that extended resection of lymph 
Table 2 Factors potentially affecting adequacy of intraoperative lymph node sampling

\begin{tabular}{|c|c|c|c|c|}
\hline Staging adequacy & Mediastinal & Station 7 & Lung/hilar & Overall \\
\hline$<64$ years $(n=1,571), n(\%)$ & $1,419(90.3)$ & - & $1,420(90.4)$ & $1,321(84.1)$ \\
\hline$\geq 64$ years $(n=1,644), n(\%)$ & $1,476(89.8)$ & - & $1,439(87.5)$ & $1,339(81.4)$ \\
\hline$P$ value & 0.607 & - & 0.01 & 0.048 \\
\hline \multicolumn{5}{|l|}{ Side } \\
\hline Left, n (\%) & $1,207(86.3)$ & $1,240(88.6)$ & $1,256(89.8)$ & $1,126(80.5)$ \\
\hline Right, n (\%) & $1,677(93.0)$ & $1,705(94.6)$ & $1,591(88.2)$ & $1,524(84.5)$ \\
\hline$P$ value & 0 & 0 & 0.17 & 0.003 \\
\hline \multicolumn{5}{|l|}{ Type of resection } \\
\hline$P$ value & 0 & 0 & 0 & 0 \\
\hline \multicolumn{5}{|l|}{ Type of approach } \\
\hline Thoracotomy $(n=2,860), n(\%)$ & $2,574(90.0)$ & $2,633(92.1)$ & $2,538(88.7)$ & $2,368(82.8)$ \\
\hline VATS ( $\mathrm{n}=355), \mathrm{n}(\%)$ & $321(90.4)$ & 324 (91.3) & $321(90.4)$ & $292(82.3)$ \\
\hline$P$ value & 0.802 & 0.603 & 0.341 & 0.798 \\
\hline \multicolumn{5}{|l|}{ T1 } \\
\hline Present $(n=1,356), n(\%)$ & $1,218(89.8)$ & - & $1,184(87.3)$ & $1,097(80.9)$ \\
\hline Absent $(n=1,859), n(\%)$ & $1,677(90.2)$ & - & $1,675(90.1)$ & $1,563(84.1)$ \\
\hline \multicolumn{5}{|l|}{ T3 } \\
\hline Present $(n=499), n(\%)$ & $448(89.8)$ & - & $460(92.2)$ & $422(84.6)$ \\
\hline Absent $(n=2,716), n(\%)$ & $2,447(90.1)$ & - & 2,399 (88.3) & $2,238(82.4)$ \\
\hline$P$ value & 0.828 & - & 0.017 & 0.239 \\
\hline \multicolumn{5}{|l|}{ T4 } \\
\hline Present $(n=217), n(\%)$ & $191(88.0)$ & - & $184(84.8)$ & $177(81.6)$ \\
\hline Absent (n=2998), n (\%) & $2,704(90.2)$ & - & 2,675 (89.2) & $2,483(82.8)$ \\
\hline$P$ value & 0.301 & - & 0.044 & 0.637 \\
\hline \multicolumn{5}{|l|}{ Postoperative course } \\
\hline Complications ( $\mathrm{n}=442), \mathrm{n}(\%)$ & $409(92.5)$ & $415(93.9)$ & $405(91.6)$ & $382(86.4)$ \\
\hline No complications ( $n=2,773), n(\%)$ & $2,486(89.6)$ & $2,542(91.7)$ & $2,454(88.5)$ & $2,278(82.1)$ \\
\hline$P$ value & 0.06 & 0.11 & 0.051 & 0.027 \\
\hline
\end{tabular}


Table 3 Adequacy of intraoperative staging stratified by tumor size

\begin{tabular}{lccccl}
\hline Tumor diameter $(\mathrm{mm})$ & $1-30(\mathrm{n}=1,618), \mathrm{n}(\%)$ & $31-50(\mathrm{n}=1,061), \mathrm{n}(\%)$ & $51-70(\mathrm{n}=363), \mathrm{n}(\%)$ & $\geq 71(\mathrm{n}=173), \mathrm{n}(\%)$ & $\mathrm{P}$ value \\
\hline Adequate mediastinal staging & $1,442(89.1)$ & $960(90.5)$ & $331(91.2)$ & $162(93.6)$ & 0.188 \\
Station subcarinal sampled & $1,478(91.3)$ & $981(92.4)$ & $335(92.3)$ & $162(93.6)$ & 0.596 \\
Adequate lung/hilar staging & $1,403(86.7)$ & $959(90.4)$ & $338(93.1)$ & $159(91.9)$ & 0.0004 \\
Overall adequate staging & $1,294(80.0)$ & $896(84.4)$ & $316(87.0)$ & $153(88.4)$ & 0.0002 \\
\hline
\end{tabular}

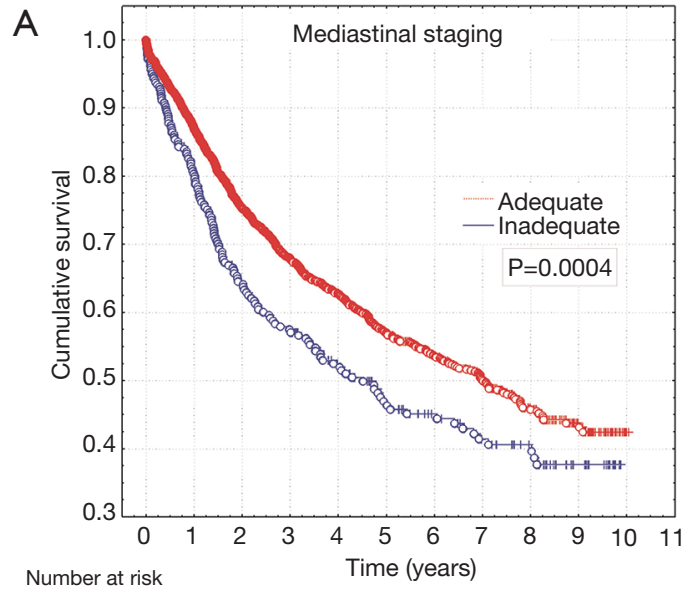

Adeq. 2,859 1,939 1,410 1,038776 $583 \quad 433 \quad 283 \quad 167 \quad 69$

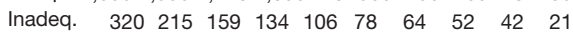

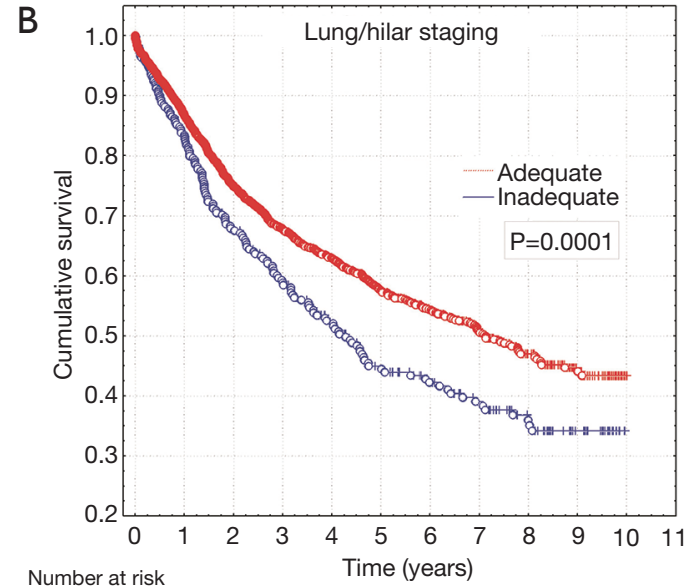

Adeq. 2,859 1,910 1,3911,026 $765 \quad 573 \quad 425 \quad 279 \quad 168 \quad 71$

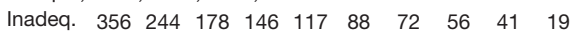

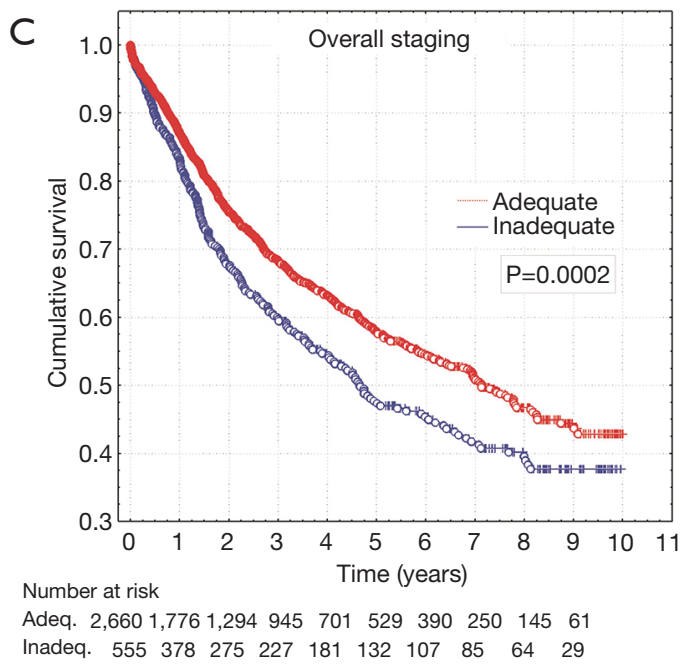

Figure 1 Survival curves for patients with adequate and inadequate mediastinal staging (A), lung and hilar staging (B) and overall nodal staging $(\mathrm{C})$.

Table 4 Rate of $\mathrm{pN}$ categories according to adequate and inadequate intraoperative nodal staging

\begin{tabular}{lccc}
\hline Overall staging & Adequate $(\mathrm{n}=2,660), \mathrm{n}(\%)$ & Inadequate $(\mathrm{n}=555), \mathrm{n}(\%)$ & $\mathrm{P}$ value \\
\hline pN0 & $1,881(70.7)$ & $461(83.1)$ & $<0.0001$ \\
pN1 & $422(15.9)$ & $40(7.2)$ & $54(9.7)$ \\
pN2 & $357(13.4)$ & & \\
\hline
\end{tabular}



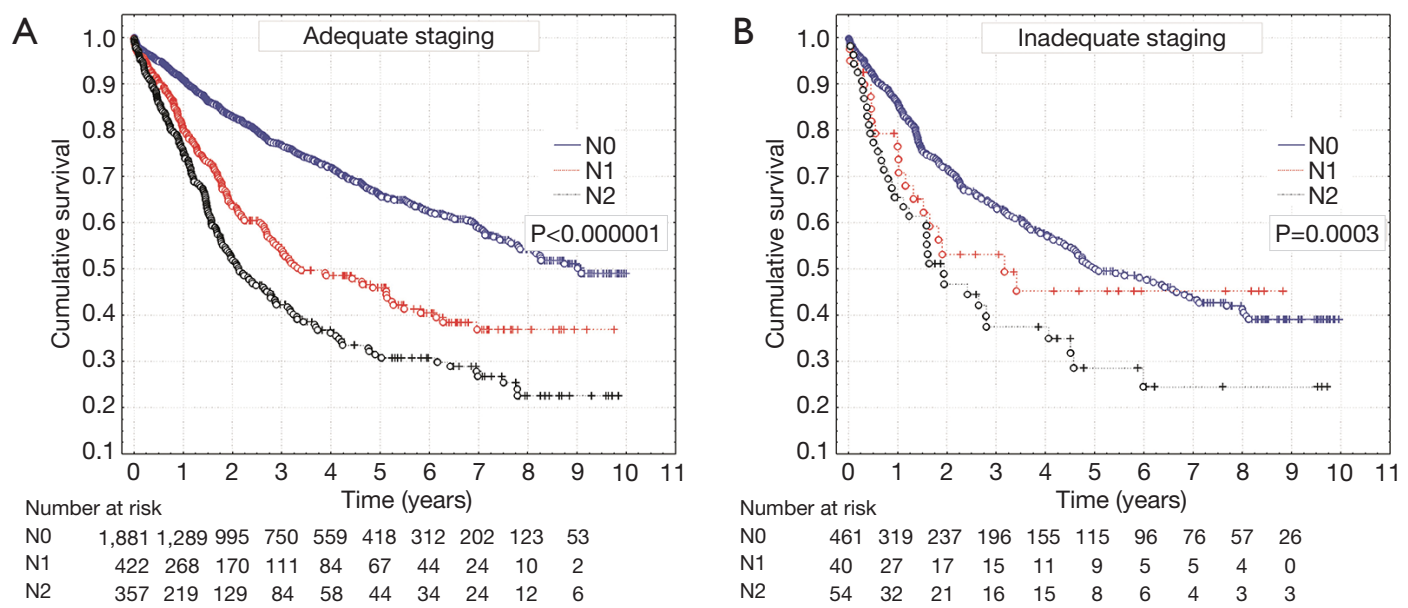

Figure 2 Survival curves for patients with adequate (A) and inadequate (B) staging according to pN0, pN1 and pN2 status.
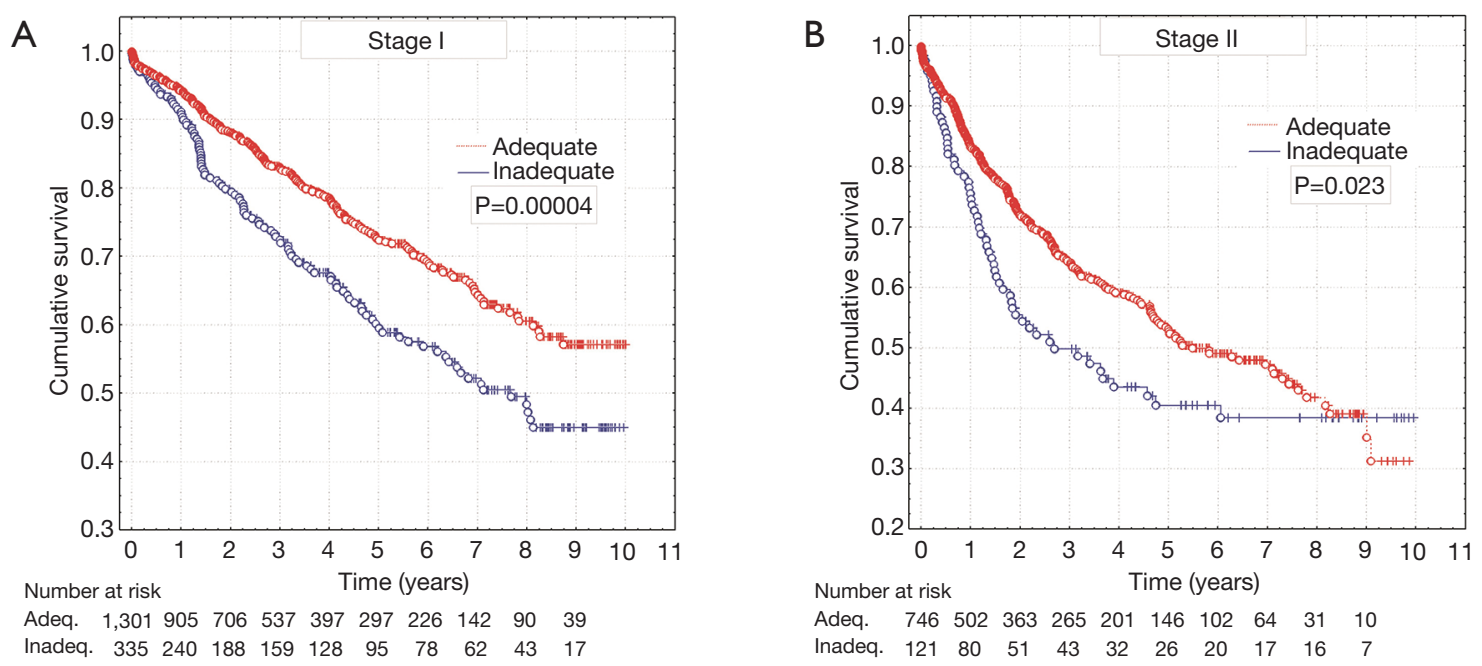

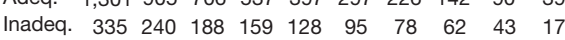

Inadeq. $\begin{array}{llllllllll}121 & 80 & 51 & 43 & 32 & 26 & 20 & 17 & 16 & 7\end{array}$

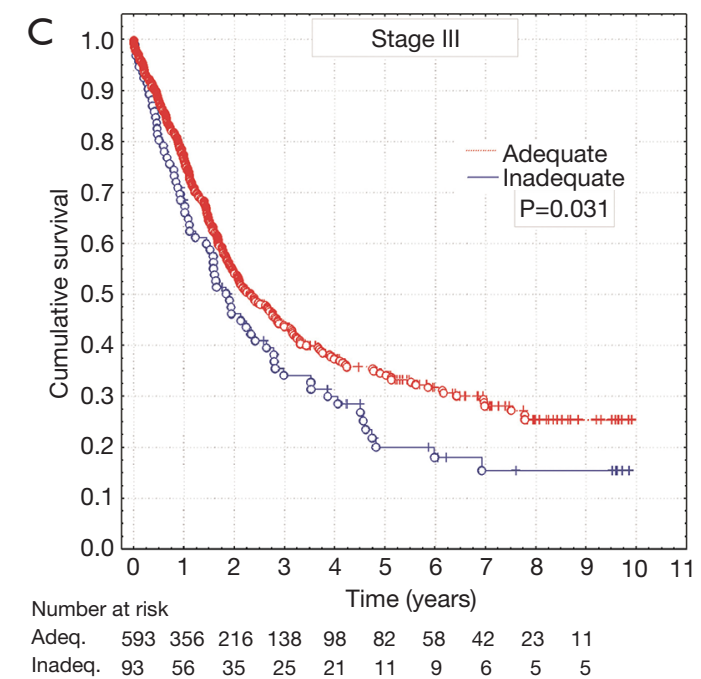

Figure 3 Survival curves for patients with adequate and inadequate overall nodal staging according to stage I (A), stage II (B) and stage III (C) non-small cell lung cancer. 
nodes improves survival rate or prolongs the disease-free survival (8). Also, there are no evidence-based guidelines defining the number of nodes and location of nodal stations, which should be sampled obligatorily in order to exclude positive $\mathrm{N}$ category. In this study the minimum criteria allowing the confirmation of $\mathrm{pN} 0$ category were those included in recommendations of the Union for International Cancer Control (UICC). They also include the minimum scope of exploration of hilum and intrapulmonary nodes, and not just mediastinum. The UICC guidelines were implemented in Wroclaw Thoracic Surgery Centre in 2009.

The years 2007-2017 have seen a gradual increase in number of patients undergoing radical resections due to NSCLC, and a statistically significant growth in trend concerning all examined parameters of $\mathrm{N}$ category staging adequacy. In line with the UICC recommendations the investigation included sampling in successive years of $\geq 3$ nodes or nodal groups of mediastinum and hilum/lung, sampling of subcarinal nodes; separate assessment concerned adequate staging of mediastinal, hilar/intrapulmonary nodes, and the overall adequate assessment of $\mathrm{N}$ category staging. A noticeable growth in the number of evaluated parameters was seen from the year 2009, after the UICC recommendation to observe the practice of intraoperative staging in the Wroclaw Thoracic Surgery Centre. A similar upward trend with regard to staging adequacy (following the implementation of IASLC recommendations) is also reported to happen in one of the British centres (9). Creation of recommendations by scientific societies or research groups with regard to intraoperative assessment of lymph nodes is therefore legitimate, as it leads to improvement of $\mathrm{N}$ category staging quality.

The problem remains that in the successive years following $2009,6 \%$ to $20 \%$ patients $(3-13 \%$ in mediastinum and $4-12 \%$ in hilum/lung area), still failed to meet the criteria of minimum staging set out by UICC. Hence, attempts were made to evaluate the factors affecting the situation. It was proved that in elderly patients $\geq 64$ years the proportion of overall staging adequacy decreased significantly $(81.4 \%$ vs. $84.1 \%$ in younger age $<64)$, and after age 75 it amounted only to $70.7 \%$. It seems that the fact does not result from the fear of risk of increased complications in old age patients after a systematic lymphadenectomy of mediastinum, as reported by some authors (10). In the evaluated material the proportion of accuracy of assessment of mediastinal nodes in two age groups did not differ materially. Research results indicate that main reason for staging inadequacy in the investigated group of elderly patients is inaccuracy of assessment of N1 group nodes $(\mathrm{P}=0.01)$. This most probably is related to a greater proportion of sublobar resections in this group of patients $(11.9 \% ; 195 / 1,644)$ compared with younger patients $(5.1 \% ; 80 / 1,571)$. It was shown that another factor considerably lowering the value of $\mathrm{N}$ category are sublobar resections, where at each researched level a less precise minimally required sampling of nodes. However, at the level of $\mathrm{N} 1$ nodes assessment, the difference in adequacy totalled as much as $66.2 \%$ (28.4\%—-sublobar vs. $94.6 \%$ lobectomy/pneumonectomy group). Smaller quantities of sampled lymph nodes in sublobar resections are also confirmed by other authors $(9,11)$. This relationship in the case of sampling of intrapulmonary nodes is connected with a smaller quantity of pulmonary parenchyma evaluated by a pathologist (as well as a smaller number of lymph nodes) and a limited exploration of interlobar area especially in case of the group of patients having undergone wedge resection. In case of mediastinal nodes, a lower quantity sampled in sublobar resections can be related to an intended need of shortening operating time and minimization of risk of complications, especially in high-risk and eldery patients. ESTS recommendations allow such possibility in this group of patients (7).

A factor significantly influencing the reduction of lymph nodes sampling is the left-side resection $(\mathrm{P}=0.003)$. In current study the reason is low adequacy of assessment of mediastinal nodes $(\mathrm{P}<0.0001)$, including subcarinal nodes $(\mathrm{P}<0.0001)$. A similar trend is seen when comparing IASLC recommendations to sampling actually carried out (9). It has to be assumed that this is related to a more difficult surgical access to some node stations on left side; this especially refers to group $4 \mathrm{~L}$ and 7 . A possible reason may also be a larger quantity of material sampled during the operation on the left side, verified by pathologists as "false lymph node", and a significantly greater proportion of the presence of nodes in the upper parts of mediastinum on the right side (12).

It was also established that there is a relation between the tumor size and the proportion of lymph node sampling accuracy. The smaller the tumor, the smaller proportion of staging accuracy $(\mathrm{P}<0.0001)$. This relation is noticeable to the tumor size $\leq 50 \mathrm{~mm}$. It is related to a less effective removal of nodes from hilum and interlobar area $(\mathrm{P}<0.0001)$. A similar dependence was observed in a separate analysis for T1 category (tumors up to $30 \mathrm{~mm}$ in diameter). A smaller proportion of correct staging of $\mathrm{N} 1$ group in case of smaller tumors most probably results from the fact that only in this group segmentectomies and wedge resections can 
be made. As previously confirmed in this study, sublobar resections display extraordinary inadequacy of hilum and intrapulmonary lymph nodes evaluation. Accuracy of assessment of mediastinal nodes in compliance with minimum guidelines of UICC was upheld on the level of $90 \%$ regardless of $\mathrm{T}$ category and the size of the tumor. It seems satisfactory that VATS approach resections form no barrier in terms of $\mathrm{N}$ category staging accuracy at all investigated levels. VATS lobectomies represented $11 \%$ of the total examined material (in $2017-33 \%$ resections in NSCLC), also including the period of steep learning curve. It is important that indications for VATS lobectomies in the investigated period, especially when the method was initially introduced, involved tumors of up to $50 \mathrm{~mm}$ in diameter.

Pathological $\mathrm{N}$ category is the strongest prognostic factor in patients treated surgically. We therefore assumed that its inaccurate assessment must result in improper prognosis and further therapeutic proceeding in part of the patients. First of all we saw a significantly higher proportion with $\mathrm{pN} 1$ category (increase by $8.7 \%$ ) and $\mathrm{pN} 2$ category (increase by $3.7 \%$ ) in patients with properly run staging. $12.4 \%$ of the patients defined as pN0 in an inadequately staged group might have had metastasis in the lymph nodes, representing a potential group of patients which should be qualified for adjuvant chemotherapy. Analysis of survival rates in patients with adequate and inadequate staging of $\mathrm{N}$ category, shows significant differences. This also refers separately to examined survival rates in terms of adequate staging, for node stations of $\mathrm{N} 1$ and $\mathrm{N} 2$ area. The patients with an inadequately staged $\mathrm{N}$ category live shorter due to the "hidden" in this group metastases to lymph nodes. In the examined stages of NSCLC (I, II and III), we also found a significantly lower survival rate in patients with inadequate staging. This confirms the prognostic power of $\mathrm{N}$ category and also shows a decisive need for exploration of mediastinum and lung nodes at least in the limited scope indicated by UICC. A proper assessment of lymph nodes is necessary even despite increased risk $(\mathrm{P}=0.027)$ of the previously mentioned complications relating to exploration of mediastinum and hilum. Most of the complications heal well and patients require only slightly longer hospitalization. It only seems legitimate to limit lymphadenectomy or sampling in patients from high-risk group.

A limitation of study is lack of detailed evaluation of the group of patients who underwent a systematic lymphadenectomy of mediastinum (e.g., in line with the guidelines of ESTS of 2006), and comparison of the data with the patients with minimal nodal assessment according to UICC guidelines, and the nodal status of the patients operated in the centre. The scope of this article makes it impossible to analyse this much data and will be the subject of further analyses and separate work. For the same reasons, examination did not include the detailed division of $\mathrm{T} 1$ or T2 category, as was analysed survival rates for the subgroups of stages I, II and III. The type of work is assumed to be retrospective, as it evaluates the accuracy of already sampled nodes compared with the proposed guidelines.

It seems that currently the legitimacy of performing at least intraoperative sampling of nodes does not raise much controversy. The study indicates however a degree of weakness in surgeons who sometimes limit the scope of resection of nodes basing on an initial clinical evaluation of the patient, extended operation time, intraoperative conditions and own experience. This results in inadequate assessment of $\mathrm{N}$ category in an average of dozen or so percentage of patients each year. A solution may be the already proposed introduction of specimen collection kits which allow intraoperative verification of at least minimally required guidelines concerning sampling of lymph nodes (13). It looks that establishing a proper staging of $\mathrm{N}$ category and confirmation of pN0 category does not concern all patients. Therefore, a regular annual monitoring should be run in thoracic centres as part of treatment effectiveness evaluation.

In conclusion, a detailed analysis of reasons resulting in an inadequate assessment of $\mathrm{N}$ category, shows the areas which can be improved in the future. Most of all this concerns the patients with sublobar resections, and elderly patients with insufficient exploration of $\mathrm{N} 1$ group nodes, left-side resections and the patients with $\mathrm{T} 1$ category. The implementation of UICC recommendations into the clinical practice was reflected in considerable growth in proportion of patients with an adequate assessment of $\mathrm{N}$ category. Despite the implemented guidelines there is still dozen or more percentage of patients with an inaccurately $\mathrm{N}$ category staging, which results in an incorrect prognosis in this group of patients and probably affects further therapeutic decisions.

\section{Acknowledgements}

None.

\section{Footnote}

Conflicts of Interest: The authors have no conflicts of interest to declare. 
Ethical Statement: The design of this retrospective and nonexperimental study was approved by the local committee on ethics of Wroclaw Thoracic Centre in Lower Silesian Centre of Lung Diseases (No. KE-08/2018), Wroclaw and all patients gave their informed consent to processing the data concerning the disease by the National Registry of Lung Cancer.

\section{References}

1. Sobin LH, Gospodarowicz MK, Wittekind C. TNM Classification of Malignant Tumours. 7th edition. Oxford: Wiley Blackwell, 2010.

2. Goldstraw P. IASLC Staging Manual in Thoracic Oncology. 1st edition. Orange Park, FL: EditorialRx Press, 2009.

3. Ettinger DS, Kris MG. Update: NCCN non-small cell lung cancer clinical practice guidelines. J Natl Compr Canc Netw 2004;2 Suppl 3:S-9-13.

4. Rusch VW, Asamura $\mathrm{H}$, Watanabe $\mathrm{H}$ et al. Members of IASLC Staging Committee. The IASLC lung cancer staging project: a proposal for a new international lymph node map in the forthcoming seventh edition of the TNM classification for lung cancer. J Thorac Oncol 2009;4:568-77.

5. Bierley JD, Gospodarowicz MK, Wittekind C. TNM Classification of Malignant Tumours. 8th edition. Oxford: Wiley Blackwell, 2017.

6. Osarogiagbon RU, Darling GE. Towards optimal pathologic staging of resectable non-small cell lung cancer.
Transl Lung Cancer Res 2013;2:364-71.

7. Lardinois D, De Leyn P, Van Schil P, et al. ESTS guidelines for intraoperative lymph node staging in non-small cell lung cancer. Eur J Cardiothorac Surg 2006;30:787-92.

8. De Leyn P, Lardinois D, Van Schil P, et al. European trends in preoperative and intraoperative nodal staging: ESTS guidelines. J Thorac Oncol 2007;2:357-61.

9. Edwards T, Balata H, Elshafi M, et al. Adequacy of Intraoperative Nodal Staging during Surgical Resection of NSCLC: Influencing Factors and Its Relationship to Survival. J Thorac Oncol 2017;12:1845-50.

10. Okami J, Higashiyama M, Asamura H, et al. Japanese Joint Committee of Lung Cancer Registry. Pulmonary resection in patients aged 80 years or over with clinical stage I non-small cell lung cancer: prognostic factors for overall survival and risk factors for postoperative complications. J Thorac Oncol 2009;4:1247-53.

11. Khullar OV, Liu Y, Gillespie T, et al. Survival After Sublobar Resection versus Lobectomy for Clinical Stage IA Lung Cancer: An Analysis from the National Cancer Data Base. J Thorac Oncol 2015;10:1625-33.

12. Ziyade S, Pinarbasili NB, Ziyade N, et al. Determination of standard number, size and weight of mediastinal lymph nodes in postmortem examinations: reflection on lung cancer surgery. J Cardiothorac Surg 2013;8:94.

13. Osarogiagbon RU, Sareen S, Eke R, et al. Audit of lymphadenectomy in lung cancer resections using a specimen collection kit and checklist. Ann Thorac Surg 2015;99:421-7.
Cite this article as: Pawelczyk K, Blasiak P, Szromek M, Nowinska K, Marciniak M. Assessment of adequacy of intraoperative nodal staging and factors influencing the lack of its compliance with recommendations in the surgical treatment of non-small cell lung cancer (NSCLC). J Thorac Dis 2018;10(8):4902-4911. doi: 10.21037/jtd.2018.07.23 